Laboratorio de Citogenética

2Laboratorio de

Inmunohistoquímica

Subdepartamento de

Anatomía Patológica.

Hospital de Valdivia.

Valdivia. Chile.

aTecnólogo Médico.

Recibido el 21 de abril de 2010, aceptado el 17 de mayo de 2011.

Correspondencia a: Dra. Ximena Barraza. Simpson \# 850. Valdivia. Laboratorio de Citogenética.

Subdepartamento de

Anatomía Patológica. Hospital de Valdivia. Valdivia. Chile.

Teléfono: 63- 263618

Fax: 63- 263828

Celular: 9.9191086

E-mail:xbarraza@surnet.cl

\section{Sarcoma mieloide. Caso clínico con trisomia 11}

\author{
ANYA LINCOPÁN S. ${ }^{1, a}$, YENNY VALENCIA M. ${ }^{2, a}$, \\ CRISTIAN CARRASCO L. ${ }^{2}$, XIMENA BARRAZA O. ${ }^{1}$
}

\section{Myeloid sarcoma. Report of one case with trisomy 11}

\begin{abstract}
Myeloid sarcoma is a form of extramedullary myeloid neoplasia. Cytogenetic characterization is hampered in the absence of invasion to the bone marrow, origin of cells that are usually studied in cytogenetic studies. We report a 13 years old male presenting with a mass in the right shoulder. A biopsy of the tumor disclosed a Myeloid Sarcoma. A conventional cytogenetic study of a bone marrow aspirate did not show $t(8 ; 21)$ translocation. A fluorescent in situ hybridization (FISH) performed in the paraffin embedded biopsy of the tumor, detected a chromosome 11 trisomy.

(Rev Med Chile 2011; 139: 914-916).
\end{abstract}

Key words: Chromosome 11 trisomy; FISH antifreeze proteins; Sarcoma, myeloid.
41 l sarcoma mieloide (SM), código ICD-O 9930/3, se define según la clasificación de OMS, como una masa tumoral de mieloblastos con o sin maduración, producida en un lugar anatómico diferente a la médula ósea. Su ubicación es variable, aunque frecuentemente se relaciona con piel, linfonodos, tracto gastrointestinal, hueso, tejidos blandos y testículos ${ }^{1}$.

Este tumor se presenta, en muchas ocasiones, fuera del contexto de una leucemia mieloide aguda, es decir, en pacientes libres de compromiso de medula ósea o, como se ha descrito en algunos pacientes, asociada a otras alteraciones mielodisplásicas o mieloproliferativas.

El pronóstico cambia si hay compromiso medular, por lo que éste siempre debe descartarse.

La falta de infiltración medular dificulta la caracterización citogenética del clon tumoral, ya que al no haber células tumorales, los estudios de citogenética convencional realizados en medula ósea, se informarán con cariotipo normal.

Como ya es reconocido, el cariotipo presente en el clon tumoral, es un factor a considerar en el pronóstico clínico, por lo que se ha intentado la caracterización citogenética por métodos alternativos a la citogenética convencional como la hibridación in situ con fluorescencia (FISH), que permite la evaluación de zonas cromosómicas específicas ${ }^{2}$ o hibridación comparativa del genoma (CGH), que da una visión más amplia de la ganancia o pérdida de zonas cromosómicas ${ }^{3}$.

Presentamos un caso de SM, estudiado en nuestro laboratorio con la técnica de hibridación in situ con fluorescencia (FISH).

\section{Caso clínico}

Paciente de sexo masculino, 13 años, derivado por aumento de volumen en la región del hombro derecho. En el examen físico se describían, además, masas en la cara interna del muslo y sobre parrilla costal, más un tumor del mediastino medioposterior, diagnosticado por radiografía de tórax.

El hemograma no presentaba características patológicas. Un estudio con ecografía de partes blandas, informó múltiples masas en región sub-dérmica localizadas en diferentes partes del cuerpo.

Se realizó biopsia del tumor, en la que se describió una neoplasia indiferenciada compuesta por células grandes, de núcleos pleomórficos que 
Sarcoma mieloide con trisomia 11 - A. Lincopán et al

crecen discohesivamente sobre una trama densamente vascular (Figura 1). Se realizó inmunohistoquímica para CD1a, CD3, CD4, CD15, CD20, CD25 (clon: 4C9), CD31, CD34, CD45(clon: PD7/26 and 2B11), CD56, CD68, CD99 (clon: 13), CD117, Mieloperoxidasa, Vimentina (clon: V9), EMA (clon: GP1.4), S-100, Tdt y Actina. Los clones identificados dieron resultado positivo. La biopsia fue informada como: hallazgos histológicos e inmunohistoquímicos compatibles con Sarcoma Mieloide.

El estudio de médula ósea por mielograma y biopsia, descartó compromiso tumoral, sólo se describieron cambios reactivos.

El inmuno fenotipo fue normal y PCR (reacción en cadena de polimerasa) en muestras de médula ósea y sangre periférica, fueron negativas para traslocaciones $(9 ; 22),(8 ; 21),(15 ; 17),(9 ; 11)$ e inv(16).

Se realizó citogenética convencional (según protocolo estándar para muestras de médula ósea en cultivo medio Marrow-max ${ }^{\circledR}$, hipotonía con $\mathrm{KCl}$ 0.075M y fijación con ácido acético-metanol) de la muestra de médula ósea obtenida por punción, que se informó en: veinte metafases, siete incompletas por pérdida de diferentes cromosomas, mientras que en tres se describió pérdida de un cromosoma 8, por lo cual la muestra fue estudiada con FISH (protocolo $\mathrm{DAKO}^{\circledR}$ ) para traslocación $(8 ; 21)$. El estudio de FISH en médula ósea para la traslocación ETO/AML1 fue negativo en 100 núcleos estudiados, y no se observó pérdida de señal ETO, lo que alejó la posibilidad de una monosomía 8 clonal.

Para caracterizar mejor el tumor, se decidió realizar el estudio de FISH en la muestra del tejido tumoral fijado en formalina e incluido en parafina, no se disponía de tejido fresco para intentar un cultivo primario del tumor.

Iniciamos la evaluación de la muestra para traslocación $(8 ; 21)$, descrita en la literatura como la aberración más frecuente en pacientes pediátricos ${ }^{1}$, seguida de inv (16) y, finalmente, MLL(11q23). Las dos primeras se informaron normales, en 100 núcleos estudiados, mientras que en el estudio de la partición de la señal para MLL en el cromosoma 11, detectamos 50\% de los núcleos con tres señales (Figura 2), sin evidencias de partición de la señal, resultado compatible con trisomía 11, aberración descrita hasta en el 2,2\% de los casos según la literatura² .

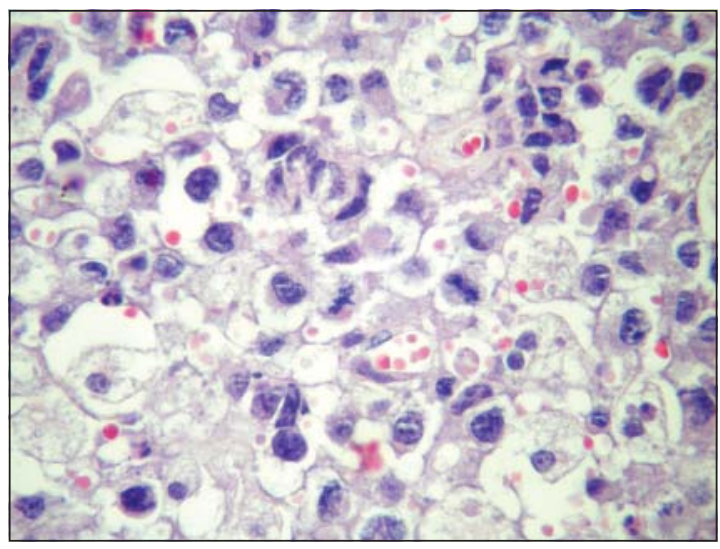

Figura 1. Tinción hematoxilina eosina, muestra núcleos pleomórficos en trama densamente vascular.

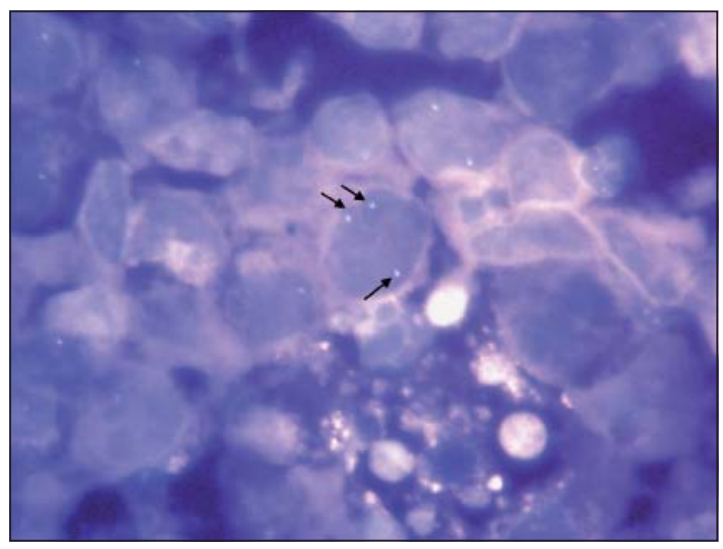

Figura 2. FISH para MLL (DAKO $®)$, muestra célula con tres señales (flechas) que marcan 11q23, sin separación de señal. Trisomía 11.

\section{Discusión}

La disponibilidad de las técnicas moleculares en citogenética ha permitido ampliar el estudio a muestras no utilizables en citogenética tradicional.

Presentamos un caso clínico de un tumor mieloide, con escasas posibilidades de caracterización citogenética por la técnica estándar, ya que el diagnóstico generalmente resulta en la disponibilidad sólo de tejido fijado y por la baja frecuencia de compromiso medular no hay tejido fresco necesario para conseguir metafases.

Por lo anterior, la complementación del estudio con técnicas moleculares como el FISH, permitió 
el diagnóstico de una aberración cromosómica, anteriormente descrita para este tumor.

Este diagnóstico podría ser de relevancia en la evolución clínica de este paciente, ya que se reconoce una asociación a mal pronóstico en la evolución clínica de tumores y la presencia de aberraciones cromosómicas,

También, la posibilidad de identificar células neoplásicas en la eventualidad de un compromiso secundario de la médula ósea.

Por lo anterior reforzamos la idea que las técnicas moleculares, son una importante herramienta complementaria en el diagnóstico anátomopatológico de un tumor, así como una ayuda en la evaluación clínica del paciente oncológico.

\section{Referencias}

1. Swerdolow SH, Campo E, Harris NL, Jafffe ES, Pileri SA, Stein H, et al. World Health Organization of Tumours of Haematopoietic and Lymphoid Tissues. Lyon: IARC Press; 2008. p. 140-1.

2. Pileri SA, Ascani S, Cox MC, Campidelli C, Bacci F, Piccoli M, et al. Myeloid sarcoma: clinico-pathologic, phenotypic and cytogenetic analysis of 92 adult patients. Leukemia 2007; 21: 340-50.

3. Deeb G, Baer M, Gaile D, JaniSait S, Barcos M, Wetzler $\mathrm{M}$, et al. Genomic profiling of myeloid sarcoma by array comparative genomic hybridization. Genes Chromosomes Cancer 2005; 44: 373-83. 